Pacific Journal of Mathematics

A GENERAL LOCAL ERGODIC THEOREM IN $\boldsymbol{L}_{1}$ 


\title{
A GENERAL LOCAL ERGODIC THEOREM IN $L_{1}$
}

\author{
M. A. Akcoglu and M. Falkowitz
}

Let $(X, \mathscr{F}, \mu)$ be a $\sigma$-finite measure space and let $L_{1}$ denote the usual Banach space of equivalence classes of real valued integrable functions on $X$. We shall not distinguish between the equivalence classes and the functions themselves. Relations between functions are assumed to hold in an a.e. sense.

Throughout this paper $\left\{T_{t}\right\}_{t>0}$ will denote a strongly continuous semigroup of linear contractions on $L_{1}$. That is:

(i) each $T_{t}$ is a linear operator on $L_{1}$, with norm not more than 1 ,

(ii) $T_{s+t}=T_{t} T_{s}$ for all $t, s>0$,

(iii) for all $f \in L_{1}$ and $t>0, \lim _{s \rightarrow t, s>0} ;\left\|T_{s} f-T_{t} f\right\|=0$. group.

We will prove the pointwise local ergodic theorem for such a semi

THEOREM 1.1. If $f \in L_{1}$, then $\lim _{t \rightarrow 0^{+}}(1 / t) \int_{0}^{t} T_{s} f d s$ exists a.e. on $X$.

Here $\int_{0}^{t} T_{s} f d s$ is defined as the strong limit of the usual Riemann sums. To give a meaning to the a.e. limit one either has to use the usual conventions in ergodic theory (p. 686 in [4]), or, equivalently, to avoid these conventions, has to restrict the range of $t$ in $\lim _{t \rightarrow 0^{+}}$to a countable dense subset of $(0, \infty)$, for example to the set of positive rational numbers (p. 200 in [3]). The same remarks also apply to Theorem 1.2 below.

Various special cases of this theorem have already been proved, going back to Wiener's local ergodic theorem [11], in which $\left\{T_{t}\right\}$ is induced by a measure preserving flow of $X$. The modern form of the theory started with the results of Krengel [6] and Ornstein [8], where the local ergodic theorem is proved under the following two additional assumptions on $\left\{T_{t}\right\}$ :

(iv) Positivity: $T_{t} L_{1}^{+} \subset L_{1}^{+}$for all $t>0$, where $L_{1}^{+}$is the positive cone of $L_{1}$,

(v) Continuity at the origin: There is an operator $T_{0}$ on $L_{1}$ such that $\lim _{t \rightarrow 0^{+}}\left\|T_{t} f-T_{0} f\right\|=0$ for all $f \in L_{1}$.

Later the theorem has been proved assuming (iv) only [1], or assuming (v) only [5], [7], [10], in addition to (i), (ii) and (iii). Here we will prove the local ergodic theorem without any additional assumptions. 
We will, in fact, prove Theorem 1.2 below, which generalizes both Theorem 1.1 and a weaker form of a differentiation theorem of AkcogluKrengel [3]. We define, as in [3], a $T_{t}$-additive process as a family $\left\{F_{t}\right\}_{t>0}$ of $L_{1}$ functions such that $F_{t}+T_{t} F_{s}=F_{t+s}$ for all $t, s>0$. If

$$
\sup _{t>0}(1 / t)\left\|F_{t}\right\|=K<\infty
$$

then $\left\{F_{t}\right\}$ is called a bounded additive process, and $K$ is called the bound of the process. Note that $F_{t}=\int_{0}^{t} T_{s} f d s$ defines a bounded additive process for any $f \in L_{1}$. Another example of an additive process is $F_{t}=$ $\left(1-T_{t}\right) f, f \in L_{1}$, which may or may not be bounded.

THEOREM 1.2. If $\left\{F_{t}\right\}_{t>0}$ is a bounded additive process with respect to $\left\{T_{t}\right\}_{t>0}$ then there is a function $f \in L_{1}$ such that $\lim _{t \rightarrow 0^{+}} 1 / t F_{t}=f$ a.e. on $X$. Furthermore, $\lim _{t \rightarrow 0^{+}} 1 / t \int_{0}^{t} T_{s} f d s=f$ a.e.

The advantage of considering additive processes is that we can then assume the continuity of $\left\{T_{t}\right\}$ at the origin, without any loss of generality. To see this we first collect a few results which will also be used later in the proof Theorem 1.2.

THEOREM $1.3([10],[5])$. Given a strongly continuous semi group $\left\{T_{t}\right\}_{t>0}$ of $L_{1}$-contractions, there exists a strongly continuous semi-group $\left\{\tau_{t}\right\}_{t>0}$ of positive $L_{1}$-contractions such that $\left|T_{t} f\right| \leq \tau_{t}|f|$ for any $t>0$ and $f \in L_{1}$.

Such a semi group $\left\{\tau_{t}\right\}_{t>0}$ will be called a linear modulus of $\left\{T_{t}\right\}_{t>0}$. Furthermore, if a linear modulus for $\left\{T_{t}\right\}$ is continuous at the origin then $\left\{T_{t}\right\}$ is also continuous at the origin (Lemma 1 in [9]).

THEOREM 1.4 ([1]). Given a strongly continuous semi group $\left\{\tau_{t}\right\}_{t>0}$ of positive $L_{1}$-contractions, there exists a unique partition $\{C, D\}$ of $X$ into two sets such that

(i) $\chi_{D} \tau_{t} f=0$ for all $t>0$ and $f \in L_{1}$,

(ii) the restriction of $\left\{\tau_{d} t\right\}_{t>0}$ to $L_{1}(C)$ is a strongly continuous semi group of $L_{1}(C)$-contractions which is also continuous at the origin.

Here $\chi$ denotes the characteristic function of its subscript and $L_{1}(C)$ $=\left\{f \mid f \in L_{1}, \chi_{D} f=0\right\}$.

Lemma 1.1. If $\left\{F_{t}\right\}$ is a bounded $T_{t}$-additive process and if $\{C, D\}$ is the partition of $X$ given in Theorem 1.4 with respect to a linear modulus $\left\{\tau_{t}\right\}$ of $\left\{T_{t}\right\}$ then $\chi_{D} F_{t}=0$ a.e. for all $t>0$. 
Proof. Let $0<\varepsilon<t$. Then

$$
\left|F_{t}\right| \leq\left|F_{\varepsilon}\right|+\left|T_{\varepsilon} F_{t-\varepsilon}\right| \leq\left|F_{\varepsilon}\right|+\tau_{\varepsilon}\left|F_{t-\varepsilon}\right|
$$

shows that $\chi_{D}\left|F_{t}\right| \leq \chi_{D}\left|F_{\varepsilon}\right|$, since $\chi_{D} \tau_{\varepsilon}\left|F_{t-\varepsilon}\right|=0$. Hence $\left\|\chi_{D}\left|F_{t}\right|\right\| \leq\left\|F_{\varepsilon}\right\|$ $\leq K \varepsilon$, where $K$ is the bound of $\left\{F_{t}\right\}$.

This lemma shows that $F_{t} \in L_{1}(C)$. If $\tilde{T}_{t}$ is the restriction of $T_{t}$ to $L_{1}(C)$, then $F_{t}$ is also a bounded $\tilde{T}_{t}$-additive process. But now $\left\{\tilde{T}_{t}\right\}$ is continuous at the origin, since $\left\{\tau_{t}\right\}$ restricted to $L_{1}(C)$ is a linear modulus for $\left\{\tilde{T}_{t}\right\}$ and is continuous at the origin. Therefore we may and do assume, in the proof of Theorem 1.2, that $\left\{T_{t}\right\}$ is continuous at the origin. (Note that this assumption can not be made in Theorem 1.1, because $f$ may not be in $L_{1} C$.)

THEOREM 1.5 ([3]). Let $\left\{\boldsymbol{H}_{t}\right\}$ be a bounded additive process with respect to a strongly continuous semigroup $\left\{\tau_{t}\right\}$ of positive $L_{1}$ contractions. Then there is an $L_{1}$ function $h$ such that $\lim _{t \rightarrow 0^{+}}(1 / t) H_{t}=h$ a.e. and such that $\lim _{t \rightarrow 0^{+}}(1 / t) \int_{0}^{t} \tau_{s} h d s=h$ a.e.

Although the final conclusion of this theorem is not explicitly stated in [3], it follows easily from (3.8) of that paper.

2. Proof of the main result. Given a bounded additive process one can construct a dominating positive additive process with respect to the linear modulus. For this the continuity at the origin is not needed.

TheOREM 2.1. Let $\left\{F_{t}\right\}_{t>0}$ be a bounded $T_{t}$-additive process and let $\left\{\tau_{t}\right\}$ be a linear modulus of $\left\{T_{t}\right\}$. Then there is a $\tau_{t}$-additive process $\left\{H_{t}\right\}$, such that (i) $\left|F_{t}\right| \leq H_{t}$ a.e. for each $t>0$, (ii) $\left\{H_{t}\right\}$ has the same bound as $\left\{F_{t}\right\}$.

Proof. Let $K=\sup _{t>0}(1 / t)\left\|F_{t}\right\|$ be the bound of $\left\{F_{t}\right\}$. To construct $H_{t}$ for a certain fixed $t$, we consider the family $\mathscr{P}$ of partitions of $[0, t]$ of the form $P=\left\{\alpha_{0}, \alpha_{1}, \ldots, \alpha_{n}\right\}$ with $0=\alpha_{0}<\alpha_{1}<\cdots<\alpha_{n}=t$ and $n \geq$ 2.

Define

$$
H_{t}^{(P)}=\left|F_{\alpha_{1}}\right|+\sum_{i=1}^{n-1} \tau_{\alpha_{t}}\left|F_{\alpha_{t+1}-\alpha_{t}}\right| .
$$

The family of $L_{1}$ functions, $\left\{H_{t}^{(P)} ; P \in \mathscr{P}\right\}$, fullfils

(1) $\sup _{P \in \mathscr{P}}\left\|(1 / t) H_{t}^{(P)}\right\| \leq K$

(2) if $P^{\prime} \in \mathscr{P}$ refines $P \in \mathscr{P}$ then $H_{t}^{(P)} \leq H_{t}^{\left(P^{\prime}\right)}$. 
The validity of (1) follows immediately from the definition and boundedness of $\left\{F_{t}\right\}$ :

$$
\begin{aligned}
\left\|\frac{1}{t} H_{t}^{(P)}\right\| & \leq\left\|F_{\alpha_{1}}\right\|+\sum_{i=1}^{n-1}\left\|\tau_{\alpha_{t}}\left|F_{\alpha_{i+1}-\alpha_{t}}\right|\right\| \\
& \leq \frac{1}{t} K\left(\alpha_{1}+\sum_{i=1}^{n-1}\left(\alpha_{i+1}-\alpha_{i}\right)\right)=K .
\end{aligned}
$$

In order to prove (2), let us first note that it is clearly sufficient to consider the case where $P=\left\{\alpha_{0}, \alpha_{1}, \ldots, \alpha_{n}\right\}$ is refined by adding one point, say $\alpha$. If $0<\alpha<\alpha_{1}$ then, indeed,

$$
\left|F_{\alpha_{1}}\right|=\left|F_{\alpha}+T_{\alpha} F_{\alpha_{1}-\alpha}\right| \leq\left|F_{\alpha}\right|+\tau_{\alpha}\left|F_{\alpha_{1}-\alpha}\right| \text {. }
$$

Similarly, for the case $\alpha_{i}<\alpha<\alpha_{i+1}$ with $1 \leq i \leq n-1$,

$$
\begin{aligned}
\tau_{\alpha_{\imath}}\left|F_{\alpha_{i+1}-\alpha_{i}}\right| & =\tau_{\alpha_{i}}\left|F_{\alpha-\alpha_{i}}+T_{\alpha-\alpha_{t}} F_{\alpha_{i+1}-\alpha}\right| \\
& \leq \tau_{\alpha_{\imath}}\left|F_{\alpha-\alpha_{\imath}}\right|+\tau_{\alpha_{i}} \tau_{\alpha-\alpha_{i}}\left|F_{\alpha_{\imath+1}-\alpha}\right| \\
& =\tau_{\alpha_{\imath}}\left|F_{\alpha-\alpha_{\imath}}\right|+\tau_{\alpha}\left|F_{\alpha_{i+1}-\alpha}\right| .
\end{aligned}
$$

Now, since for any two partitions there is one that refines both (take their union), there is a sequence $P_{i} \in \mathscr{P}$ such that $H_{t}^{\left(P_{t}\right)}$ is increasing and $\lim _{i \rightarrow \infty}\left\|H_{t}^{(P i)}\right\|=\sup _{P \in \mathscr{P}}\left\|H_{t}^{(P)}\right\|$. We define

$$
H_{t}=\lim _{i \rightarrow \infty} H_{t}^{\left(P_{t}\right)} \text { a.e. }
$$

Clearly any other such sequence would yield the same limit. Since for any partition of the form $P=\{0, \alpha, t\}$ we have

$$
\left|F_{t}\right|=\left|F_{\alpha}+T_{\alpha} F_{t-\alpha}\right| \leq\left|F_{\alpha}\right|+\tau_{\alpha}\left|F_{t-\alpha}\right|=H_{t}^{(P)}
$$

(i) is proved. Considering (1) above, we also have (ii). The proof of the theorem will be completed by showing the additivity of $\left\{H_{t}\right\}$ with respect to $\left\{\tau_{t}\right\}$.

Fix $t>0, s>0$ and consider arbitrary partitions $P^{\prime}=\left\{\alpha_{0}, \ldots, \alpha_{n}\right\}$ and $P^{\prime \prime}=\left\{\beta_{0}, \ldots, \beta_{m}\right\}$ with $n \geq 2, m \geq 2$, of $[0, t]$ and $[0, s]$ respectively. Denote by $P^{\prime} P^{\prime \prime}$ the partition $\left\{\alpha_{0}, \ldots, \alpha_{n}, t+\beta_{i}, \ldots, t+\beta_{m}\right\}$ of $[0, t+s]$. Then

$$
\begin{aligned}
H_{t+s}^{\left(P^{\prime} P^{\prime \prime}\right)}= & \left|F_{\alpha_{1}}\right|+\sum_{i=1}^{n-1} \tau_{\alpha_{t}}\left|F_{\alpha_{t+1}-\alpha_{t}}\right|+\tau_{\alpha_{n}}\left|F_{t+\beta_{1}-\alpha_{n}}\right| \\
& +\sum_{i=1}^{m-1} \tau_{t+\beta_{t}}\left|F_{t+\beta_{t+1}-t-\beta_{t}}\right|=H_{t}^{\left(P^{\prime}\right)}+\tau_{t} H_{s}^{\left(P^{\prime \prime}\right)}
\end{aligned}
$$


Let then $\left\{P_{i}^{\prime}\right\}$ and $\left\{P_{i}^{\prime \prime}\right\}$ be sequences of partitions such that the sequences $H_{t}^{\left(P_{t}^{\prime}\right)}$ and $H_{s}^{\left(P_{t}^{\prime \prime}\right)}$ are increasing and converge to $H_{t}$ and $H_{s}$

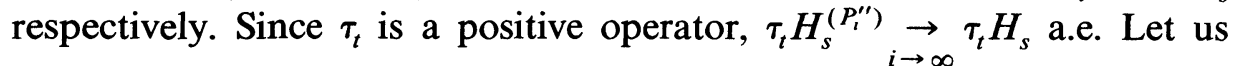
take limits, as $i \rightarrow \infty$, in

$$
H_{t+s}^{\left(P_{t}^{\prime} P_{i}^{\prime \prime}\right)}=H_{t}^{\left(P_{t}^{\prime}\right)}+\tau_{t} H_{s}^{\left(P_{i}^{\prime \prime}\right)} .
$$

Since the left-hand side is increasing, by our definition $H_{t+s} \geq$ $\lim _{i \rightarrow \infty} H_{t+s}^{\left(P_{t}^{\prime} P_{t}^{\prime \prime}\right)}$, and we obtain $H_{t+s} \geq H_{t}+\tau_{t} H_{s}$. On the other hand, given a partition $P$ of $[0, t+s]$, refine it (if necessary) to include the point $t$, and consider $P^{\prime}$ and $P^{\prime \prime}$, on $[0, t]$ and $[0, s]$ respectively: $P^{\prime}$ is the partition induced by $P$ on $[0, t]$ and $P^{\prime \prime}$ is the one induced by $P$ on $[t, t+s]$ and "shifted" to $[0, s]$. A similar argument, choosing a sequence $P_{i}$ such that $P_{i+1}$ refines $P_{i}, t \in P_{i}$ and $H_{t+s}^{\left(P_{i}\right)}$ converges to $H_{t+s}$ a.e., shows

$$
H_{t+s} \leq \lim _{i \rightarrow \infty} H_{t}^{\left(P_{t}^{\prime}\right)}+\tau_{t} \lim _{i \rightarrow \infty} H_{s}^{\left(P_{t}^{\prime \prime}\right)} \leq H_{t}+\tau_{t} H_{s} .
$$

Note that in the construction above we actually use only the process $\left\{\left|F_{t}\right|\right\}_{t>0}$ and the semigroup $\left\{\tau_{t}\right\}$. The additivity of $\left\{F_{t}\right\}$ with respect to $\left\{T_{t}\right\}$ makes $\left\{\left|F_{t}\right|\right\}$ subadditive with respect to $\left\{\tau_{t}\right\}$; that is $\left|F_{t+s}\right| \leq\left|F_{t}\right|+$ $\tau_{t}\left|F_{s}\right|$ for all $t>0, s>0$. Thus we have the following theorem.

THEOREM 2.2. A bounded positive process, subadditive with respect to a strongly continuous semigroup of positive linear contractions, has a dominating, positive and additive process, with the same bound.

In proving Theorem 1.2 we shall find it convenient to use the following notation: $f_{t}=(1 / t) F_{t}, h_{t}=(1 / t) H_{t}$; also, w-lim and s-lim will denote the weak and strong limits in $L_{1}$. The $L_{1}$ function $f$ in Theorem 1.2 shall be obtained as the limit of a weakly convergent sequence. It is known that a bounded sequence in $L_{1}$ which is dominated by a fixed $L_{1}$ positive function is weakly sequentially compact (see Theorem IV.8.9 in [4]). For our purposes a certain sharpening of that result is needed.

LEMMA 2.1. Let $\phi_{n} \in L_{1}$ and $\left|\phi_{n}\right| \leq \psi_{n} \in L_{1}^{+}$such that there exists $\psi \in L_{1}^{+}$with $\left\|\psi_{n}-\psi\right\| \underset{n \rightarrow \infty}{\rightarrow} 0$. Then $\left\{\phi_{n}\right\}$ is weakly sequentially compact.

Proof. Let $\psi_{n}^{\prime}=\psi_{n} \wedge \psi$; then $0 \leq \psi_{n}^{\prime} \leq \psi_{n}$. Now write $\phi_{n}$ as $\phi_{n}=$ $\phi_{n}^{\prime}+\phi_{n}^{\prime \prime}$ where

$$
\begin{aligned}
& \phi_{n}^{\prime}=\left(-\psi_{n}^{\prime}\right) \vee\left(\phi_{n} \wedge \psi_{n}^{\prime}\right) \\
& \phi_{n}^{\prime \prime}=\phi_{n}-\phi_{n}^{\prime} .
\end{aligned}
$$


For the sequence $\phi_{n}^{\prime}$ we have $\left|\phi_{n}^{\prime}\right| \leq \psi$ and by the theorem mentioned above is weakly sequentially compact. As for $\phi_{n}^{\prime \prime}$, by definition

$$
\left|\phi_{n}^{\prime \prime}\right|=\left|\phi_{n}-\phi_{n}^{\prime}\right| \leq \psi_{n}-\psi_{n}^{\prime} \leq\left|\psi_{n}-\psi\right| \text {. }
$$

This implies that $\left\|\phi_{n}^{\prime \prime}\right\| \underset{n \rightarrow \infty}{\rightarrow} 0$.

We shall also need the following fact; here again continuity at the origin is not needed.

LeMma 2.2. For any $t>0, F_{t}=\mathrm{s}-\lim _{\varepsilon \rightarrow 0^{+}} \int_{0}^{t} T_{s} f_{\varepsilon} d s$.

Proof.

$$
\begin{aligned}
\int_{0}^{t} T_{s} f_{\varepsilon} d s & =\frac{1}{\varepsilon} \int_{0}^{t} T_{s} F_{\varepsilon} d s=\frac{1}{\varepsilon} \int_{0}^{t}\left(F_{s+\varepsilon}-F_{s}\right) d s \\
& =\frac{1}{\varepsilon} \int_{\varepsilon}^{t+\varepsilon} F_{s} d s-\frac{1}{\varepsilon} \int_{0}^{t} F_{s} d s .
\end{aligned}
$$

For $\varepsilon<t$ we get

$$
\int_{0}^{t} T_{s} f_{\varepsilon} d s=\frac{1}{\varepsilon} \int_{t}^{t+\varepsilon} F_{s} d s-\frac{1}{\varepsilon} \int_{0}^{\varepsilon} F_{s} d s .
$$

Now, since the process is bounded, the first term converges in norm to $F_{t}$, whereas the second term converges to zero.

Proof of Theorem 1.2. Let $H_{t}$ be the dominating positive process for $F_{t}$, constructed in Theorem 2.1. Let $\lim _{t \rightarrow 0^{+}}(1 / t) H_{t}=\lim _{t \rightarrow 0^{+}} h_{t}=h$ a.e., as given in Theorem 1.5. Define a process $H_{t}^{\prime}$ by

$$
H_{t}^{\prime}=\int_{0}^{t} \tau_{s} h d s
$$

and consider the decomposition

$$
H_{t}=H_{t}^{\prime}+H_{t}^{\prime \prime} \text {. }
$$

Then the following holds:

$$
H_{t}^{\prime \prime} \text { is positve and } \lim _{t \rightarrow 0^{+}}(1 / t) H_{t}^{\prime \prime}=0 \text { a.e. }
$$

To see that, we take any sequence $\varepsilon_{n} \rightarrow 0$ and consider the sequence $\psi_{n}=h_{\varepsilon_{n}} \wedge h$. Then $0 \leq \psi_{n} \leq h$ and, obviously, $\psi_{n} \rightarrow h$ a.e. Being bounded by $h \in L_{1}$, by the dominated convergence theorem it also converges in norm:

$$
\left\|h-\psi_{n}\right\|=\int\left(h-\psi_{n}\right) d \mu \underset{n \rightarrow \infty}{\rightarrow} 0 .
$$


Since $\int_{0}^{t} \tau_{s} g d s$, for a fixed $t$, acting on $g \in L_{1}$, is a bounded linear operator in $L_{1}$, we also got

$$
\operatorname{s-lim}_{n \rightarrow \infty} \int_{0}^{t} \tau_{s} \psi_{n} d s=\int_{0}^{t} \tau_{s} h d s .
$$

Therefore, using Lemma 2.2,

$$
H_{t}=\underset{n \rightarrow \infty}{s-\lim } \int_{0}^{t} \tau_{s} h_{\varepsilon_{n}} d s \geq \mathrm{s}-\lim _{n \rightarrow \infty} \int_{0}^{t} \tau_{s} \psi_{n} d s=\int_{0}^{t} \tau_{s} h d s=H_{t}^{\prime} .
$$

Pointwise convergence of $(1 / t) H_{t}^{\prime \prime}$ to zero is given in Theorem 1.5.

Now we obtain the $L_{1}$ function $f$ in Theorem 1.2. Let

$$
\phi_{n}=\left(-\psi_{n}\right) \vee\left(f_{\varepsilon_{n}} \wedge \psi_{n}\right) \text {. }
$$

Then $\left|\phi_{n}\right| \leq \psi_{n}$, so that the sequences $\phi_{n}$ and $\psi_{n}$ fullfil the condition of Lemma 2.1 (with $\psi$ in the Lemma equal to $h$ ). Thus, by passing to a subsequence, if necessary, we may assume that $\phi_{n}$ converges weakly, say to $f^{*} \in L_{1}$. Put $f=T_{0} f^{*}$. Define a process $F_{t}{ }^{\prime}=\int_{0}^{t} T_{s} f d s$ and consider the decomposition $F_{t}=F_{t}^{\prime}+F_{t}^{\prime \prime}$. By the results in [5], [7] and [10], $\lim _{t \rightarrow 0^{+}}(1 / t) F_{t}^{\prime}=T_{0} f=f$ a.e. Hence the proof shall be completed by showing that $\lim _{t \rightarrow 0^{+}}(1 / t) F_{t}^{\prime \prime}=0$ a.e. This will follow from $\left|F_{t}^{\prime \prime}\right| \leq H_{t}^{\prime \prime}$, which we now prove.

Observe, first, as in the proof of Lemma 2.1, that we have $\left|f_{\varepsilon_{n}}-\phi_{n}\right|$ $\leq h_{\varepsilon_{n}}-\psi_{n}$. To evalaute $F_{t}^{\prime \prime}$ express $F_{t}, F_{t}^{\prime}, H_{t}$ and $H_{t}^{\prime}$ as the limits of integrals. From Lemma 2.2:

$$
F_{t}=\operatorname{s-lim}_{n \rightarrow \infty} \int_{0}^{t} T_{s} f_{\varepsilon_{n}} d s \quad \text { and } \quad H_{t}=\mathrm{s}_{n \rightarrow \infty} \lim _{0}^{t} \tau_{s} h_{\varepsilon_{n}} d s
$$

actually only weak convergence will be needed. Since $\int_{0}^{t} T_{s} g d s$ (or $\int_{0}^{t} \tau_{s} g d s$ ) applied to $g \in L_{1}$ is a bounded linear operator,

$$
\begin{aligned}
f^{*} & =\underset{n \rightarrow \infty}{\mathrm{w}-\lim _{n}} \phi_{n} \quad \text { implies } \\
\int_{0}^{t} T_{s} f d s & =\int_{0}^{t} T_{s} f^{*} d s=\underset{n \rightarrow \infty}{\mathrm{w}-\lim } \int_{0}^{t} T_{s} \phi_{n} d s, \text { and } \\
h & =\underset{n \rightarrow \infty}{\mathrm{s}-\lim _{n \rightarrow \infty}} \psi_{n} \quad \text { implies } \\
\int_{0}^{t} \tau_{s} h d s & =\underset{n \rightarrow \infty}{\mathrm{s}-\lim _{n \rightarrow \infty}} \int_{0}^{t} \tau_{s} \psi_{n} d s \quad\left(=\underset{n-\lim }{\mathrm{w}} \int_{0}^{t} \tau_{s} \psi_{n} d s\right) .
\end{aligned}
$$

Now

$$
\begin{aligned}
F_{t}^{\prime \prime} & =F_{t}-\int_{0}^{t} T_{s} f d s=\underset{n \rightarrow \infty}{\mathrm{w}-\lim _{0}} \int_{0}^{t} T_{s} f_{\varepsilon_{n}} d s-\underset{n \rightarrow \infty}{\mathrm{w}-\lim _{0}} \int_{0}^{t} T_{s} \phi_{n} d s \\
& =\underset{n \rightarrow \infty}{\mathrm{w}-\lim } \int_{0}^{t} T_{s}\left(f_{\varepsilon_{n}}-\phi_{n}\right) d s .
\end{aligned}
$$


Since $\left|f_{\varepsilon_{n}}-\phi_{n}\right| \leq h_{\varepsilon_{n}}-\psi_{n}$, this gives

$$
\begin{aligned}
\left|F_{t}^{\prime \prime}\right| & \leq \underset{n \rightarrow \infty}{\mathrm{w}-\lim } \int_{0}^{t} \tau_{s}\left(h_{\varepsilon_{n}}-\psi_{n}\right)=\mathrm{w}-\lim \int_{0}^{t} \tau_{s} h_{\varepsilon_{n}} d s \\
& =\underset{n \rightarrow \infty}{\mathrm{w}-\lim } \int_{0}^{t} \tau_{s} \psi_{n} d s=H_{t}-\int_{0}^{t} \tau_{s} h d s=H_{t}^{\prime \prime} .
\end{aligned}
$$

This completes the proof.

\section{REFERENCES}

[1] M. A. Akcoglu and R. V. Chacon, A local ratio theorem, Canad. J. Math., 22 (1970), 545-552.

[2] M. A. Akcoglu and A. del Junco, Differentiation of n-dimensional additive processes, Canad. J. Math., 33 (1981), 749-768.

[3] M. A. Akcoglu and U. Krengel, A differentiation theorem for additive processes, Math. Z., 163 (1978), 199-210.

[4] N. Dunford and J. T. Schwartz, Linear Operators, Part I, Interscience Publishers Inc., New York, 1958.

[5] C. Kipins, Majoration des semi-groupes de contractions de $L_{1}$ et applications, Ann. Inst. Poincaré sect. B, 10 (1974), 369-384.

[6] U. Krengel, A local ergodic theorem, Invent. Math., 6 (1969), 329-333.

[7] Y. Kubokawa, Ergodic theorems for contraction semi-groups, J. Math. Soc. Japan, 27 (1975), 184-193.

[8] D. S. Ornstein, The sums of iterates of a positive operator, Advances in Prob. and related topics, 2 (1970), 87-115.

[9] R. Sato, $A$ note on a local ergodic theorem, Comment. Math. Univ. Carolinae, 16 (1975), 1-11.

[10] Contraction semi-groups in Lebesgue space, Pacific J. Math., 78 (1978), 251-259.

[11] N. Wiener, The ergodic theorem, Duke Math. J., 5 (1939), 1-18.

Received June 21, 1982. Research supported in part by the NSERC Grant A3974.

UNIVERSITY OF TORONTO

TORONTO, ONTARIO, CANADA M5S 1A1 


\section{PACIFIC JOURNAL OF MATHEMATICS EDITORS}

\author{
V. S. VARADARAJAN (Managing Editor) \\ University of California \\ Los Angeles, CA 90024 \\ Charles R. DePrima \\ California Institute of Technology \\ Pasadena, CA 91125 \\ R. FInN \\ Stanford University \\ Stanford, CA 94305
}

\section{HeRmanN FlaschKa \\ University of Arizona \\ Tucson, AZ 85721}

Ramesh A. Gangolli

University of Washington

Seattle, WA 98195

ROBION KIRBY

University of California

Berkeley, CA 94720

\section{C. MOORE}

University of California

Berkeley, CA 94720

\section{H. SAMELSON}

Stanford University

Stanford, CA 94305

HAROLD STARK

University of California, San Diego

La Jolla, CA 92093

\section{ASSOCIATE EDITORS}
R. ARENS
E. F. BECKENBACH
B. H. NeumanN
F. Wolf
K. Yoshida (1906-1982)

\section{SUPPORTING INSTITUTIONS}
CALIFORNIA INSTITUTE OF TECHNOLOGY

\author{
UNIVERSITY OF SOUTHERN CALIFORNIA \\ STANFORD UNIVERSITY \\ UNIVERSITY OF HAWAII \\ UNIVERSITY OF TOKYO \\ UNIVERSITY OF UTAH \\ WASHINGTON STATE UNIVERSITY \\ UNIVERSITY OF WASHINGTON
}
UNIVERSITY OF OREGON

\begin{abstract}
UNIVERSITY OF ARIZONA
UNIVERSITY OF BRITISH COLUMBIA

UNIVERSITY OF CALIFORNIA

MONTANA STATE UNIVERSITY

UNIVERSITY OF NEVADA, RENO

NEW MEXICO STATE UNIVERSITY

OREGON STATE UNIVERSITY
\end{abstract}

The Supporting Institutions listed above contribute to the cost of publication of this Journal, but they are not owners or publishers and have no responsibility for its content or policies.

Mathematical papers intended for publication in the Pacific Journal of Mathematics should be in typed form or offset-reproduced (not dittoed), double spaced with large margins. Please do not use built up fractions in the text of the manuscript. However, you may use them in the displayed equations. Underline Greek letters in red, German in green, and script in blue. The first paragraph must be capable of being used separately as a synopsis of the entire paper. In particular it should contain no bibliographic references. Please propose a heading for the odd numbered pages of less than 35 characters. Manuscripts, in triplicate, may be sent to any one of the editors. Please classify according to the scheme of Math. Reviews, Index to Vol. 39. Supply name and address of author to whom proofs should be sent. All other communications should be addressed to the managing editor, or Elaine Barth, University of California, Los Angeles, California 90024.

There are page-charges associated with articles appearing in the Pacific Journal of Mathematics. These charges are expected to be paid by the author's University, Government Agency or Company. If the author or authors do not have access to such Institutional support these charges are waived. Single authors will receive 50 free reprints; joint authors will receive a total of 100 free reprints. Additional copies may be obtained at cost in multiples of 50 .

The Pacific Journal of Mathematics is issued monthly as of January 1966. Regular subscription rate: $\$ 190.00$ a year (5 Vols., 10 issues). Special rate: $\$ 66.00$ a year to individual members of supporting institutions.

Subscriptions, orders for numbers issued in the last three calendar years, and changes of address should be sent to Pacific Journal of Mathematics, P.O. Box 969, Carmel Valley, CA 93924, U.S.A. Old back numbers obtainable from Kraus Periodicals Co., Route 100, Millwood, NY 10546.

The Pacific Journal of Mathematics at P.O. Box 969, Carmel Valley, CA 93924 (ISSN 0030-8730) publishes 5 volumes per year. Application to mail at Second-class postage rates is pending at Carmel Valley, California, and additional mailing offices. Postmaster: Send address changes to Pacific Journal of Mathematics, P.O. Box 969, Carmel Valley, CA 93924.

PUBLISHED BY PACIFIC JOURNAL OF MATHEMATICS, A NON-PROFIT CORPORATION

Copyright $\odot 1985$ by Pacific Journal of Mathematics 


\section{Pacific Journal of Mathematics}

Vol. 119, No. $2 \quad$ June, 1985

Mustafa Agah Akcoglu and Meira Falkowitz (Soshniak), A general local

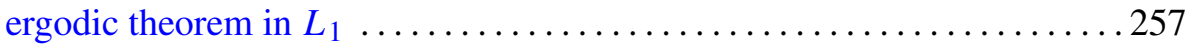

W. Wistar (William) Comfort and Lewis Chandlee Robertson,

Cardinality constraints for pseudocompact and for totally dense

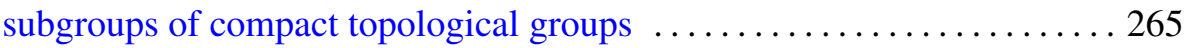

John Morse Delaurentis and Boris G. Pittel, Random permutations and

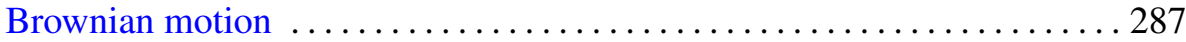

José Esteban Galé, Gel'fand theory in algebras of differentiable functions on Banach spaces ......................................... 303

Harry Gingold, On the location of zeroes of oscillatory solutions of

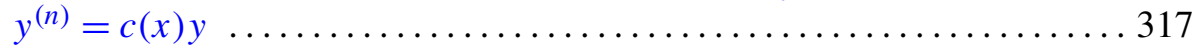

Kei Ji Izuchi, Zero sets of interpolating Blaschke products .............337

Mahesh Nerurkar, Ergodic continuous skew product actions of amenable

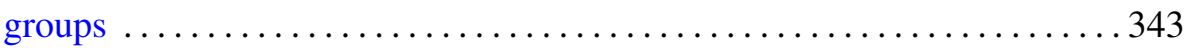

R. Owens, A maximal function characterization of a class of Hardy

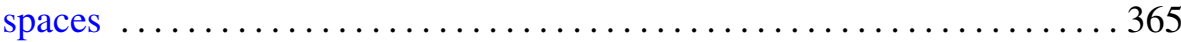

Judith Anne Packer, Point spectrum of ergodic abelian group actions and the corresponding group-measure factors $\ldots \ldots \ldots \ldots \ldots \ldots \ldots \ldots \ldots \ldots \ldots \ldots$

Judith Anne Packer, On the embedding of subalgebras corresponding to quotient actions in group-measure factors $\ldots \ldots \ldots \ldots \ldots \ldots \ldots \ldots . \ldots 4$

Iain Raeburn and Joseph L. Taylor, The bigger Brauer group and étale cohomology

David Rosen, The Diophantine equation $a x+b y=c$ in $Q(\sqrt{5})$ and other number fields

Mau-Hsiang Shih and Kok Keong Tan, Noncompact sets with convex sections

Lee Barlow Whitt, Codimension two isometric immersions between Euclidean spaces

Rodney Ian Yager, Iwasawa theory for the anticyclotomic extension 